\title{
Patterns of gene action in plant development revealed by enhancer trap and gene trap transposable elements
}

\author{
Venkatesan Sundaresan, ${ }^{1,4}$ Patricia Springer, ${ }^{1}$ Thomas Volpe, ${ }^{1}$ Samuel Haward, ${ }^{1,3}$ \\ Jonathan D.G. Jones, ${ }^{2}$ Caroline Dean, ${ }^{2}$ Hong $M a,{ }^{1}$ and Robert Martienssen ${ }^{1}$ \\ ${ }^{1}$ Cold Spring Harbor Laboratory, Cold Spring Harbor, New York 11724 USA; ${ }^{2}$ John Innes Centre, Norwich, UK
}

\begin{abstract}
The crucifer Arabidopsis thaliana has been used widely as a model organism for the study of plant development. We describe here the development of an efficient insertional mutagenesis system in Arabidopsis that permits identification of genes by their patterns of expression during development. Transposable elements of the $A c / D s$ system carrying the GUS reporter gene have been designed to act as enhancer traps or gene traps. A novel selection scheme maximizes recovery of unlinked transposition events. In this study 491 plants carrying independent transposon insertions were generated and screened for expression patterns. One-half of the enhancer trap insertions and one-quarter of the gene trap insertions displayed GUS expression in seedlings or flowers, including expression patterns specific to organs, tissues, cell types, or developmental stages. The patterns identify genes that act during organogenesis, pattern formation, or cell differentiation. Transposon insertion lines with specific GUS expression patterns provide valuable markers for studies of Arabidopsis development and identify new cell types or subtypes in plants. The diversity of gene expression patterns generated suggests that the identification and cloning of Arabidopsis genes expressed in any developmental process is feasible using this system.
\end{abstract}

[Key Words: Arabidopsis development; plant development; enhancer trap; gene trap; transposable elements]

Received April 14, 1995; revised version accepted June 15, 1995.

McClintock's investigations on alterations in the patterns of "gene action" in maize kernels led to the discovery of transposable elements (McClintock 1950). Subsequently, transposable elements have been found in almost all organisms examined and are believed to constitute a major agent for the generation of evolutionary diversity through mutations and genome rearrangements. The widespread distribution and mutagenic potential of these elements have led to their exploitation as valuable tools in genetic and molecular studies of prokaryotic and eukaryotic organisms. In particular, transposon mutagenesis has provided a means of cloning developmentally important genes from many higher eukaryotes, where cloning by complementation is not feasible. This successful utilization of transposon mutagenesis has led to the development of new approaches for gene identification and cloning, as described below.

In recent years the study of development in animals has been facilitated greatly by technologies using engineered insertion elements called enhancer traps and gene traps (for review, see Skarnes 1990; Wilson et al. 1990). The enhancer trap or gene trap element carries a reporter

${ }^{3}$ Present address: Department of Plant Sciences, Cambridge University, Cambridge, UK.

${ }^{4}$ Corresponding author. gene construct that can respond to cis-acting transcriptional signals at the site of insertion. These elements permit the identification of genes by their pattern of expression and their subsequent cloning using the inserted element as a tag. A particularly useful aspect of this technology is that it permits the identification of genes that would have been missed in conventional mutagenesis screens. Many genes have multiple roles, acting at early as well as late stages in development, so that their later functions are obscured in phenotypic screens but are revealed in screens for gene expression patterns (Mlodzik et al. 1990; Wilson et al. 1990). Second, if a gene is functionally redundant because of the presence of a second locus that can subsitute for the same function, inactivation of the gene will not result in any phenotype. In the yeast Saccharomyces cerevisiae, it is estimated that $60 \%-70 \%$ of the genes have no phenotype upon disruption (Goebl and Petes 1986; Oliver et al. 1992; Burns et al. 1994). Such genes cannot be identified in screens for mutant phenotypes but may be detected by expression pattern in enhancer trap or gene trap screens.

In the last decade, the crucifer Arabidopsis thaliana has been used widely as a model system for studying plant development. Maize transposons can be made to transpose at sufficiently high rates in Arabidopsis to permit gene tagging and cloning (Aarts et al. 1993; Bancroft 
et al. 1993; Long et al. 1993). Here we describe the establishment of a transposon system for generating gene trap and enhancer trap insertions in higher plants. We have engineered elements of the $A c-D s$ family of transposable elements, first described by McClintock, to act as gene traps or as enhancer traps in Arabidopsis. We have used a novel selection scheme that overcomes a limitation of this transposon system by selecting against closely linked transpositions. By generating several hundred independent insertion lines, we have obtained plants carrying diverse patterns of reporter gene expression, many of which reflect specific developmental programs. The collection of insertions described not only can be used to clone the corresponding chromosomal genes but also provides a set of specific markers for different organs and tissues, and for identifying cell types. This system can be adapted easily to a large scale for the identification and cloning of genes involved in various stages of plant development.

\section{Results}

\section{Design of the transposable elements}

Enhancer trap elements carry a reporter gene with a weak or minimal promoter (O'Kane and Gehring 1987; Bellen et al. 1989; Bier et al. 1989; Wilson et al. 1989). When the element inserts in the proximity of a chromosomal gene, the result is expression of the reporter gene under control of the neighboring chromosomal enhancers. If the insertion is within the transcribed region of the gene, a mutant phenotype may also be observed in homozygotes. Gene trap elements do not carry a promoter but, instead, rely on transcription from the chromosomal gene for reporter gene expression (Gossler et al. 1989; Kerr et al. 1989; Friedrich and Soriano 1991।. Splice acceptor sites are introduced in front of the coding region of the reporter gene to facilitate the production of fusion proteins should the reporter integrate within an intron. As described below, both types of elements were used in this study.

We have utilized a two-element transposon system in which transgenic Arabidopsis plants carrying an immobilized $A c$ element are crossed to plants carrying one of two different $D s$ elements (i.e., nonautonomous $A c$ elements|. The immobilized $A c$ element contains a cauliflower mosaic virus (CaMV) $35 \mathrm{~S}$ promoter-Ac transposase fusion that generates high $D s$ excision frequencies in trans (Scofield et al. 1993). This Ac element lacks one of the $A c$ termini and therefore cannot transpose, but it supplies transposase constitutively (Fig. 1A).

Two types of $D s$ elements were constructed for this study. They are shown schematically in Figure 1, B and $C$, and are described in detail in Materials and methods. The $D s$ elements contain a $\beta$-glucuronidase (uidA or GUS) reporter gene, the expression of which can be visualized by simple histochemical staining (Jefferson 1987), and which is able to tolerate large amino-terminal fusions (Kavanagh et al. 1988). The enhancer trap element $D S E$ (Fig. 1B) is designed so that expression of the
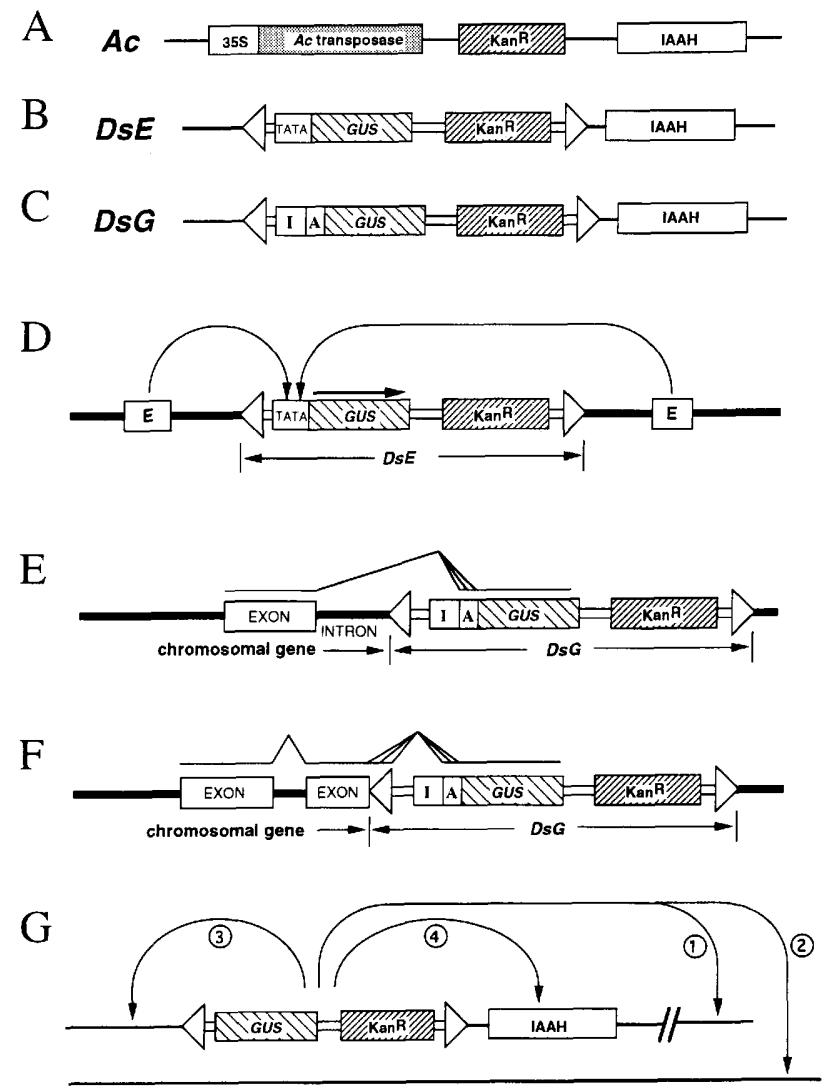

Figure 1. $(A) A c$ element in T-DNA vector; $(B) D s E$ element in T-DNA vector; $(C) D s G$ element in T-DNA vector; $(D)$ expression from $D s E$ element inserted near a chromosomal enhancer; $(E)$ expression from $D s G$ element inserted into an intron; $(F)$ expression from $D s G$ element inserted into an exon $i(G)$ possible transpositions of $D s$ element from T-DNA. (1) Unlinked or loosely linked transposition to same chromosome; (2) unlinked transposition to different chromosome; (3) closely linked transposition; (4) closely linked transposition into IAAH gene. (IAAH) Indole acetic acid hydrolase gene conferring sensitivity to NAM; (TATA) minimal promoter; (I) Arabidopsis intron: (A), triple splice acceptor. Open arrowheads indicate the ends of the $D$ s elements. Sequences in $A, B$, and $C$ are flanked by T-DNA borders that are not shown. For details, see Materials and methods, and Fig. 8.

reporter gene is dependent on its insertion near chromosomal enhancer sequences (Fig. 1D). The GUS reporter gene is fused to a minimal promoter derived from the $35 \mathrm{~S}$ promoter of CaMV. The element also carries a NPTII gene, which confers resistance to kanamycin as a selectable marker.

The gene trap $D s$ element $D s G$ (Fig. $1 \mathrm{C}$ ), is designed to detect the expression of a gene when the element is inserted within a transcribed region. Instead of the minimal promoter-GUS fusion used in DsE, DsG contains an intact but promoterless GUS gene, with intron sequences ( $\mathrm{I}$ in Fig. $\mathrm{IC}$ ) fused upstream of the GUS ATG codon. Two additional consensus splice acceptor sequences ( $\mathrm{A}$ in Fig. $1 \mathrm{C}$ ), have been added using an oligonucleotide, so that there is a splice acceptor in every 
reading frame. If the $D s G$ element transposes into the intron of a chromosomal gene, with the GUS gene in the correct orientation, we expect to get splicing from the splice donor of the chromosomal intron to the splice acceptors in front of the GUS gene (Fig. 1E).

Introns in plants are small relative to those in animals, so that intron sequences constitute a significantly smaller fraction of plant genomes. Therefore, it may be important to ensure that a gene trap element used in plants will also function when it inserts into exons. In designing the $D s G$ element, we have exploited the existence of multiple splice donor sites at the end of the Ds element (Wessler et al. 1987, 1988). When the DsG element inserts into an exon, the sequence between the splice donor sites at the end of the element and the splice acceptors introduced in front of the GUS gene can be spliced out from the transcript, resulting in a GUS fusion expressed under the control of the chromosomal gene (Fig. 1F).

To establish the Arabidopsis starter lines carrying Ac and $D s$, the $A c$ and $D s$ elements were subcloned into T-DNA vectors for Agrobacterium-mediated transformation of Arabidopsis plants of the Landsberg erecta ecotype (see Materials and methods). The kanamycin resistance gene within the T-DNA region was used to select for transgenic plants. The T-DNA vectors also carry the indole acetic acid hydrolase (IAAH) gene (Fig. 1A-C), which is used for counter-selection (see below). Transgenic plants with single T-DNA insertions were propagated and used as the starter lines in the crosses described below. These starter lines are now available from the Arabidopsis Stock Center at Ohio State University (Columbus). In this study three $A c$ starter lines (Ac1, Ac2, Ac5; Arabidopsis Stock Center, accession nos. CS8043-CS8045), three DsE starter lines (DsE1, DsE2, DsE3; Arabidopsis Stock Center, accession nos. 6-CS8048), and one DsG starter line (DsGl; Arabidopsis Stock Center, accession no. CS8049|, have been used (Materials and methods).

\section{Selection for plants carrying transposed Ds elements}

The ability to generate a large number of transposed elements distributed throughout the genome is important for random insertional mutagenesis. The $35 \mathrm{~S}-A c$ transposase fusion used in this study generates high frequencies of forward transposition in Arabidopsis (Swinburne et al. 1992) and thus fulfills part of this requirement. However, a serious limitation is imposed by a wellknown feature of the $A c-D s$ transposon system, that is, preferential transposition to sites that are closely linked to the donor site (Dooner and Belachew 1989; Jones et al. 1990; Bancroft and Dean 1993). To overcome this limitation, we have used a novel selection scheme to enrich for unlinked transposition events.

In our scheme we select for transposition by simultaneously selecting against the IAAH-linked donor site of the Ds element by using naphthalene acetamide (NAM), and for the presence of a transposed Ds carrying the NPTII gene by using kanamycin (Fig. 1G). The IAAH gene confers sensitivity of the plants to NAM by conversion of NAM to the potent auxin naphthalene acetic acid (NAA), and, consequently, can be used as a counter-selectable marker (Karlin-Neumann et al. 1991). In the same step, we also select against the IAAH-linked immobilized $A c$ element. The frequency of recovery of these transposed $D s$ elements will be proportional to the recombination distance between the donor locus and the transposed element, so that this selection allows the recovery of $D s$ elements that have transposed to locations unlinked or loosely linked to the donor site (transpositions 1 and 2 in Fig. 1G), and excludes transposed Ds elements that are closely linked to the donor site (transposition 3).

Transposition of the $D s$ elements was initiated by crossing plants homozygous for DsE or DsG to plants homozygous for $A c$ (Fig. 2A). In the Fl plants from this cross, transpositions of the $D s$ to new sites will occur. The F1 plants were allowed to self, and in the F2 generation, the transposed $D s$ elements were selected as follows. Approximately $1000 \mathrm{~F} 2$ seeds from each F1 plant were plated onto agar plates containing kanamycin and NAM, and germinated, as described in Materials and

A

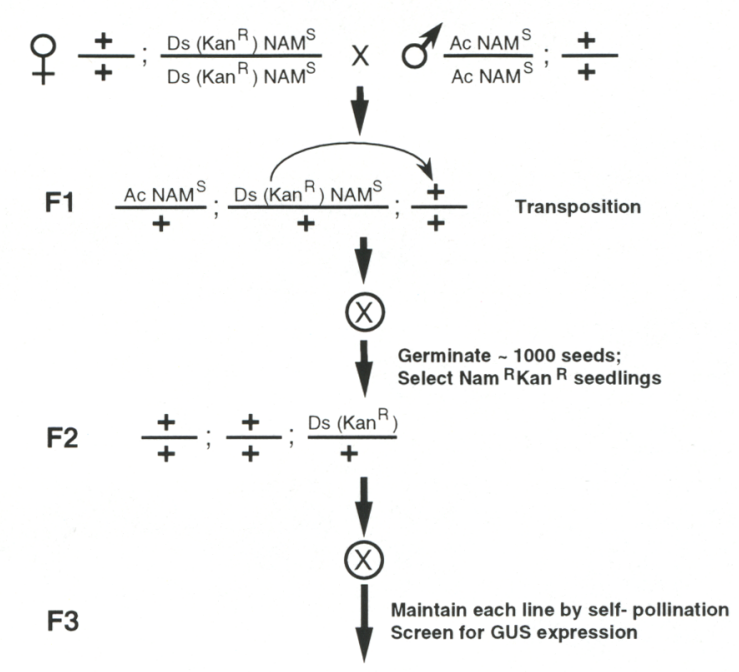

B
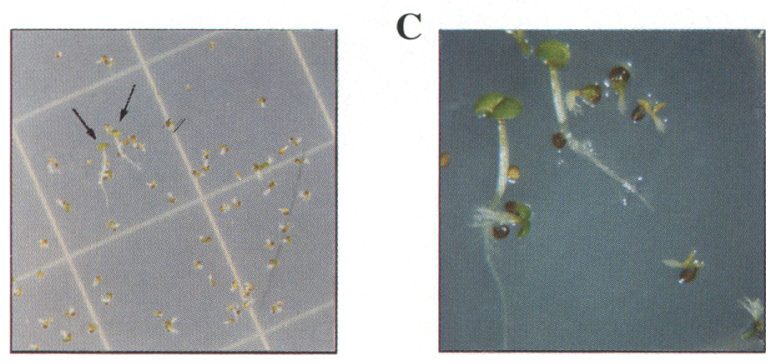

Figure 2. $(A \mid$ Generation of lines carrying transposed $D s$ elements by selection for unlinked transposition events; $(B)$ selection plate showing $\operatorname{Kan}^{\mathrm{R}} \mathrm{NAM}^{\mathrm{R}}$ seedlings (arrows); $(C)$ Closeup of seedlings in $B$. The tall green seedlings are $\operatorname{Kan}^{\mathrm{R}} N A M^{\mathrm{R}}$. $\mathrm{NAM}^{\mathrm{S}}$ seedlings are stunted, with short proliferative roots; $\mathrm{Kan}^{\mathrm{s}}$ seedlings are yellow. 
methods. Seedlings that inherit either the donor site of the $D s$, or the $A c$ element, will carry at least one copy of the IAAH gene, and will be sensitive to NAM; such seedlings are distinguished by their stunted growth and short, hairy, and proliferative roots (Karlin-Neumann et al. 1991). As outlined in Figure 2A, one-sixteenth of the F2 seeds will be $\mathrm{NAM}^{\mathrm{R}}$, as they will not inherit either copy of the IAAH gene (this ratio will be lower if the Ac is linked to the donor $D s$; see below). Most of these $\mathrm{NAM}^{\mathrm{R}}$ seedlings will be $\mathrm{Kan}^{\mathrm{S}}$ and will appear yellow or white. $\mathrm{NAM}^{\mathrm{R}}$ seedlings that have inherited a transposed Ds element will be $\mathrm{Kan}^{\mathrm{R}}$ and have normal green pigmentation on the selection medium. $\mathrm{Kan}^{\mathrm{R}} \mathrm{NAM}^{\mathrm{R}}$ seedlings can be identified easily by their normal appearance (green color, normal size, and root morphology), even in a pool of 1000 seedlings/ $150-\mathrm{mm}$ plate (Fig. $2 \mathrm{~B}, \mathrm{C}$ ). The $\mathrm{Kan}^{\mathrm{R}} \mathrm{NAM}^{\mathrm{R}}$ seedlings, representing putative transpositions, are referred to as transposants following the nomenclature of Bellen et al. (1989). They are rescued from the selection plate and transferred to soil for propagation and further characterization.

Figure 3 shows Southern blot analysis of DNA from 13 randomly selected $\mathrm{Kan}^{\mathrm{R}} N A M^{\mathrm{R}}$ progeny from independent F1 plants. When probed with an internal fragment of $D s$, the $\operatorname{Kan}^{\mathrm{R}} \mathrm{NAM}^{\mathrm{R}}$ plants were found to carry a hybridizing fragment of the same size as the internal frag-

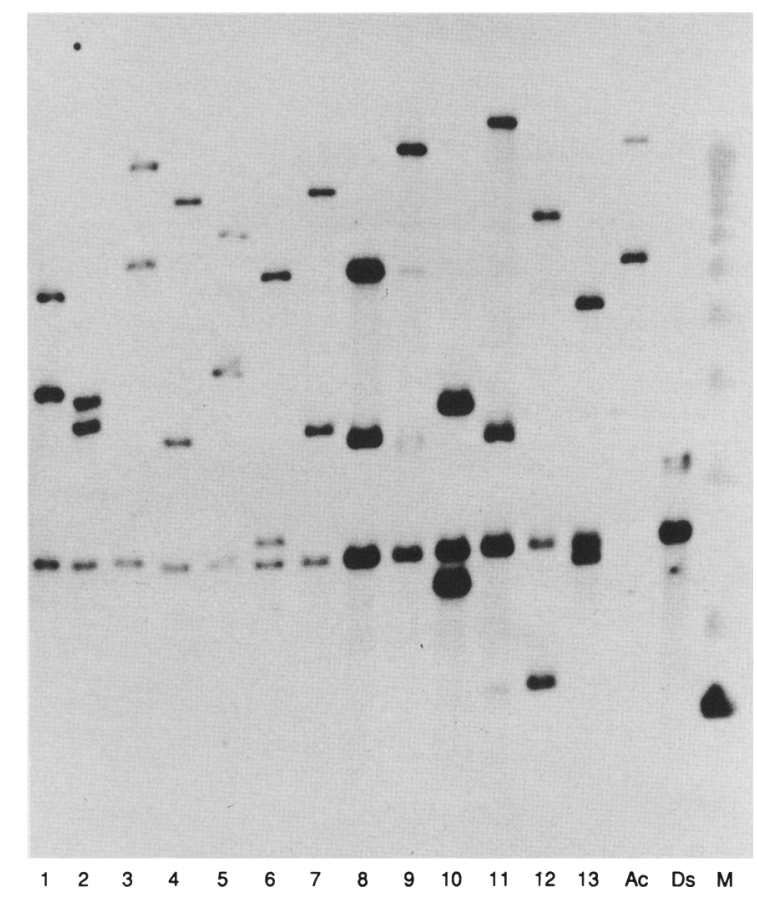

Figure 3. Southern blot of DNA from 13 randomly selected Kan $^{\mathrm{R}}$ NAM $^{\mathrm{R}} \mathrm{F} 2$ progeny of different $\mathrm{F} 1$ plants of $A c 1 \times \mathrm{DsG} 1$. The DNAs were digested with $E$ coRI, and the probe used was a $D s G$ fragment that also hybridizes to $A c$. (Lanes 1-13) $\mathrm{Kan}^{\mathrm{R}}$. $\mathrm{NAM}^{\mathrm{R}}$ individuals; (Ac) Acl parent; (Ds) DsGl parent; (M) size markers ( $k b$ ladder). The open arrows show the border fragments of the DsG element in the DsG1 parent; the solid arrow shows the internal fragment of $D s G$. ment of Ds (Fig. 3, solid arrow). All of the DNAs from $\mathrm{Kan}^{\mathrm{R}} \mathrm{NAM}^{\mathrm{R}}$ plants also contained new border fragments for the Ds element in each plant (lanes 1-13), but none had the border fragments of the Ds parent (lane Ds, open arrows) or the internal and border fragments of the parent carrying the immobilized $A c$ (lane Ac). Reprobing the same blot with a probe for the IAAH gene confirmed that none of the $\operatorname{Kan}^{\mathrm{R}} \mathrm{NAM}^{\mathrm{R}}$ progeny carried the IAAH gene (data not shown). These results indicate that both the $D s$ donor locus and the immobilized $A c$ have been selected against, and that each of the $\mathrm{Kan}^{\mathrm{R}} \mathrm{NAM}^{\mathrm{R}}$ plants carried a single transposed $D s$ element at a new chromosomal site.

In Figure $4 \mathrm{~A}$, the frequencies of $\operatorname{Kan}^{\mathrm{R}} \mathrm{NAM}^{\mathrm{R}}$ progeny for $300 \mathrm{Fl}$ plants from crosses of DsGl to Acl are shown. One-half of the Fl plants had no $\operatorname{Kan}^{\mathrm{R}} \mathrm{NAM}^{\mathrm{R}}$ progeny, suggesting that in these plants there were either no Ds transpositions or transpositions only to closely linked sites. Approximately another one-third of the F1 plants (96) generated between $0.1 \%$ and $0.4 \% \mathrm{Kan}^{\mathrm{R}} \mathrm{NAM}^{\mathrm{R}}$ progeny. Very few Fl plants $(8)$ generated $>2 \% \operatorname{Kan}^{\mathrm{R}} \mathrm{NAM}^{\mathrm{R}}$ progeny. We note that since only one-sixteenth (i.e., $6.25 \%$ ) of the progeny can be $\mathrm{NAM}^{\mathrm{R}}$, a single unlinked transposition early in the development of the $\mathrm{Fl}$ plant is unlikely to generate $>3 \% \mathrm{Kan}^{\mathrm{R}} \mathrm{NAM}^{\mathrm{R}}$ progeny, based on the frequencies of forward transposition observed previously with the $35 \mathrm{~S}-A c$ transposase fusion (from $5 \%$ to $50 \%$ in the F2 generation; Long et al. 1993). Sets of DNAs from several Kan ${ }^{R} N^{\prime} M^{R}$ progeny of a single F1 plant were analyzed by Southern blotting. In the majority of cases, all $\mathrm{Kan}^{\mathrm{R}} \mathrm{NAM}^{\mathrm{R}}$ progeny from a single $\mathrm{Fl}$ parent carried transposed $D s$ elements with border fragments of the same sizes, implying that they were derived from a single transposition event that occurred early in the development of the F1 plant (Fig. 4B). These results indicate that propagating a single $\operatorname{Kan}^{\mathrm{R}} \mathrm{NAM}^{\mathrm{R}}$ progeny from each $\mathrm{Fl}$ plant (derived from a single selection plate) will maintain a collection of independent transposition events.

Because the probability of a seedling inheriting the transposed $D s$ element, but not the donor locus, is proportional to the genetic distance spanned by the transposition event, double selection for $\mathrm{Kan}^{\mathrm{R}}$ and $\mathrm{NAM}^{\mathrm{R}}$ is expected to result in a significant enrichment for unlinked transpositions. Selection against the $A c$ element is also necessary to ensure that the recovered $D s$ transpositions remain stable and that the patterns of reporter gene expression are not affected by secondary transpositions. We have assumed the $A c$ and donor $D s$ loci to be unlinked, which is the case for the elements used in this study. However, we can expect some instances where the two loci will be linked in repulsion, resulting in a significant reduction in the recovery of $\operatorname{Kan}^{\mathrm{R}} \mathrm{NAM}^{\mathrm{R}}$ progeny. Therefore, each combination of $A c$ and $D s$ starter lines should be tested for linkage before proceeding with large-scale mutagenesis.

One type of linked transposition that can also generate $\mathrm{Kan}^{\mathrm{R}}{ }^{\mathrm{NAM}}{ }^{\mathrm{R}}$ progeny is a transposition of the $D s$ element into the IAAH gene, resulting in its inactivation /transposition 4 in Fig. 1G). Such transpositions can be iden- 

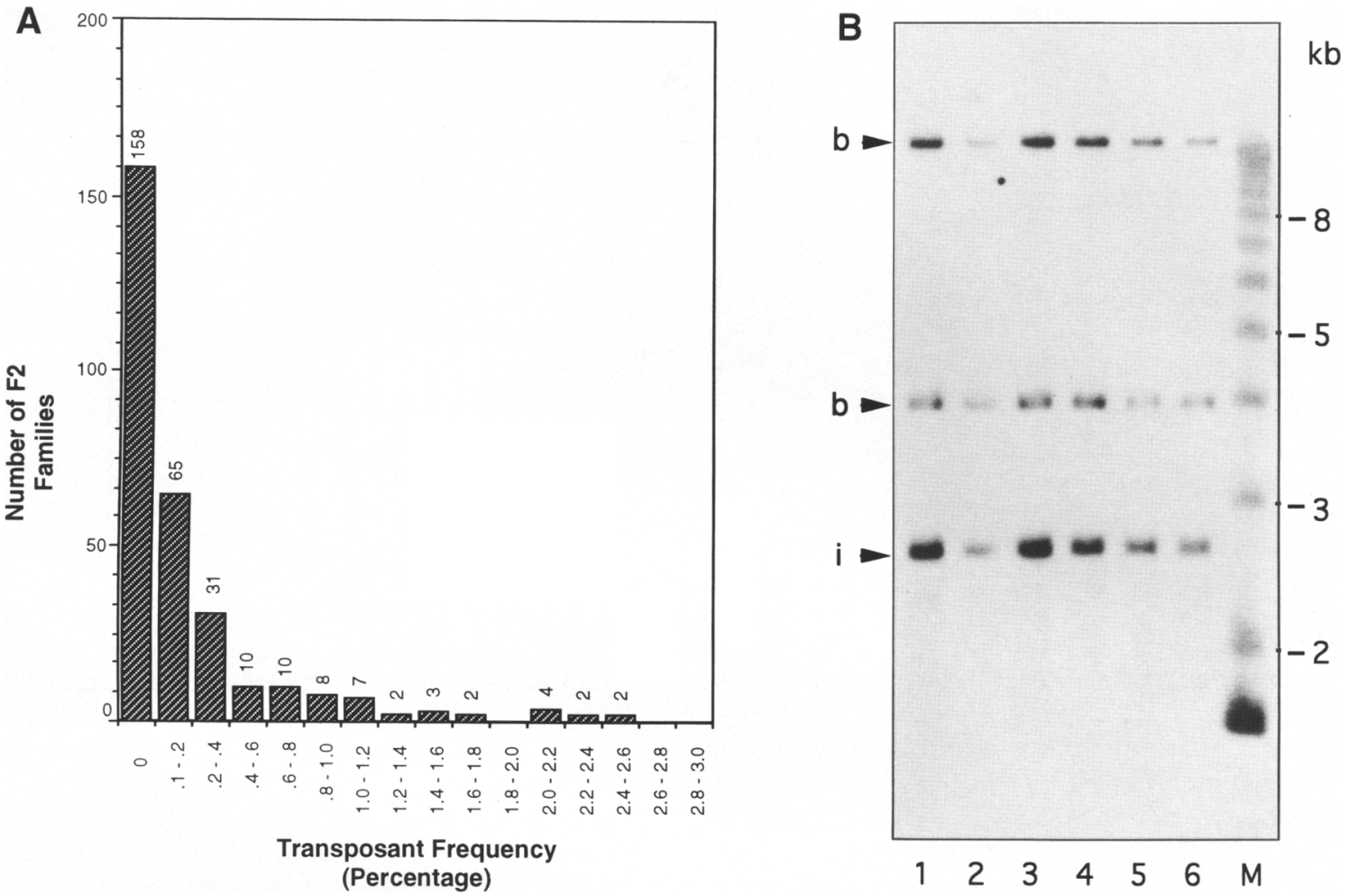

Figure 4. (A) Frequency with which $\mathrm{Kan}^{\mathrm{R}} \mathrm{NAM}^{\mathrm{R}}$ transposants occur in $\mathrm{F} 2$ families. The data represent $304 \mathrm{~F} 2$ families from a cross of $A c l$ and DsGl. (B) Southern blot of DNA from six $\operatorname{Kan}^{\mathrm{R}} \mathrm{NAM}^{\mathrm{R}}$ progeny of the same Fl parent, digested with EcoRI and probed with $D s G$. (M) Size markers (kb ladder); (i) internal fragment of $D s G$; (b) border fragments of $D s G$.

tified by the presence of the IAAH gene and other donor site sequences in the DNA of the $\operatorname{Kan}^{\mathrm{R}} \mathrm{NAM}^{\mathrm{R}}$ progeny. Transpositions into the IAAH gene were found in $\sim 4 \%$ of $>50$ independent insertions surveyed by Southern blotting. GUS expression from these insertions is under the control of the $2^{\prime}$ promoter driving the IAAH gene, resulting in staining for GUS activity throughout the seedling with especially strong staining in the roots / not shown). We have developed a simple PCR screen to identify insertions into the IAAH gene, in which the presence of the IAAH gene in the plant is detected by amplification using primers specific to the IAAH gene (P. Springer, unpubl.). However, this type of transposition is a relatively small fraction of the total number of independent transpositions. Furthermore, because an insertion into the IAAH gene results in ubiquitous GUS expression, it is automatically eliminated in any screen for specific patterns of expression. Finally, the IAAH insertions do not result in mutant phenotypes. For these reasons, we do not find it necessary to routinely use the PCR screen to identify IAAH insertions.

\section{Distribution of transposed Ds elements}

To ascertain whether the $\mathrm{Kan}^{\mathrm{R}} \mathrm{NAM}^{\mathrm{R}}$ selection results in enrichment for unlinked transpositions, we determined the map positions of transposed DsG elements in $\operatorname{Kan}^{\mathrm{R}} \mathrm{NAM}^{\mathrm{R}}$ progeny and compared them with that of the donor DsG locus. Flanking DNA probes for 24 of 36 independent transposed $D s G$ elements, and for the T-DNA borders of the starter DsG locus, could be generated by inverse PCR (IPCR) using one of three restriction enzymes for each insertion (see Materials and methods). Restriction fragment-length polymorphisms (RFLPs) between the Landsberg erecta and Columbia ecotypes were detected for probes from four of the transposed $D s G$ elements, as well as for the donor $D s G$ locus. These RFLPs allowed us to map the probes using a recombinant inbred (RI) population generated from crosses of Landsberg and Columbia (Lister and Dean 1993). As shown in Figure 5, the donor DsG locus (DsG1) mapped to chromosome 2, whereas the transposed DsG elements mapped to chromosomes 1 (GT13 and GT45), 3 (GT51), and 4 (GT148). In addition, IPCR probes from some transposed $D s G$ elements were hybridized to filters containing a yeast artificial chromosome (YAC) library obtained from J. Ecker (Guzman and Ecker 1988). Two probes were mapped in this manner, one to chromosome 3 (GT11), and the second to a position on chromosome 2 that is approximately $17 \mathrm{cM}$ from the donor locus (GT42). Therefore, transposed DsG elements obtained using the $\mathrm{Kan}^{\mathrm{R}} \mathrm{NAM}^{\mathrm{R}}$ double selection are not clustered near the donor locus but appear to be mostly unlinked to the donor locus as well as to each other.

Similar results were obtained by estimating the genetic distances of transposed $D s$ elements from the do- 
Figure 5. Schematic drawing of Arabidopsis chromosomes, showing distribution of transposed $D s G$ elements in gene trap insertion lines (GTs), relative to the donor locus DsG1. Lines indicate nearby RFLP markers and loci. (Solid arrowhead) Donor locus DsG1; (shaded arrowheads) transposed $D s G$ elements mapped using recombinant inbred lines; (open arrowheads) transposed DsG elements mapped using the YAC library.

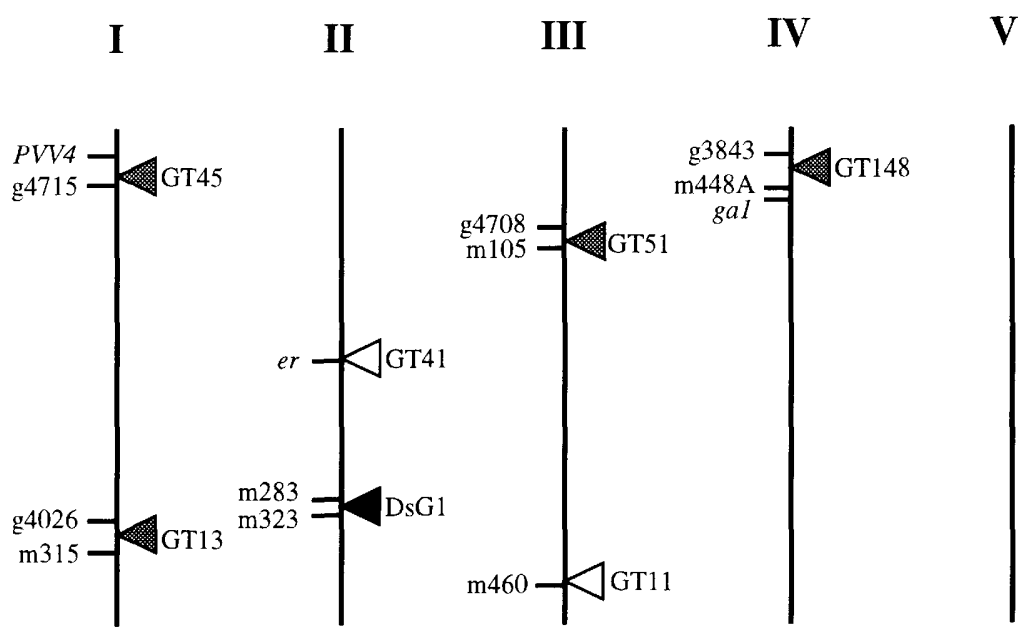

nor loci (Materials and methods). Three of four transposed $D s$ elements tested were found to be unlinked to the donor locus. The fourth transposed $D s$ element was linked to the donor $D s E$ locus, the estimated genetic distance from the donor site being $18 \mathrm{cM}$ /data not shown).

\section{Screening for expression patterns}

The $\operatorname{Kan}^{\mathrm{R}} \mathrm{NAM}^{\mathrm{R}}$ seedlings, referred to as transposants, are propagated to establish individual lines. As described above, we do not maintain more than one transposant line per F1 plant, so as to ensure a collection of independent insertions. To examine GUS expression patterns in the enhancer trap and gene trap transposants, F3 plants representing progeny of transposants containing either the enhancer trap DsE element (ET lines) or the gene trap Ds G element (GT lines) were analyzed. Staining for GUS expression in whole seedlings, and in flowers, was performed as described in Materials and methods.

Of 214 ET transposant lines examined, 104 (48\%) displayed restricted GUS expression, whereas another $4 \%$ showed ubiquitous GUS expression. The frequency of GUS-expressing GT transposant lines was lower: Of 246 gene trap transposant lines examined in this screen, 64 $(26 \%)$ displayed restricted GUS expression, with another $2.5 \%$ showing ubiquitous GUS expression. Figures 6 and 7 show 12 examples of expression patterns specific to different developmental stages and organs, and these are summarized in Table 1.

Enhancer trap GUS staining patterns are shown in Figure 6. Patterns at the seedling stage include ET206, with staining in the hypocotyl, particularly in the guard cells and the vasculature (Fig. 6A); ET220, with staining in the distal half of leaf primordia and the entire mature leaf (Fig 6B, data not shown); ET58 with GUS staining in the root hairs (Fig. 6C); and ET51 with GUS staining in the root cap (Fig. 6D). GUS staining patterns in flowers include staining in the petals, especially at the tips (ET195; Fig. 6E) and staining in the carpel walls (ET153; Fig. 6F). In ET206 (Fig. 6A), in addition to the staining in the guard cells and vasculature of the hypocotyl (Fig. 6A), GUS staining was also present in the shoot meristem but not in the cotyledons or leaves (not shown), although these organs also have guard cells.

Examples of gene trap GUS staining patterns are shown in Figure 7. At the seedling stage, these patterns include staining in a zone of the shoot apical meristem (GT185; Fig. 7A), staining in leaf primordia (GT257; Fig. 7B), and staining in trichomes (GT70; Fig. 7C). In GT70, GUS staining is strong in young trichomes, and weak or absent in old trichomes (Fig. 7C; proximal vs. distal trichomes on the leaf). Floral expression patterns include staining in the filaments of the stamens (GT56; Fig. 7D), staining in the carpels (GT142; Fig. 7E), and staining in the margins of the carpel walls (GT140; Fig. 7F). As with enhancer traps, gene trap transposants with GUS expression in multiple organs were frequently observed. In GT56, in addition to staining of the stamens shown in Figure 7D, GUS staining was also observed in the hypocotyls and cotyledons of seedlings.

Table 2 shows a summary of the frequencies of staining patterns observed in the transposant lines. Certain classes of expression patterns are not included in these data. One such class is ubiquitous expression, which could be attributable to insertions into the IAAH counter-selection gene. Another class consists of some common staining patterns that are repeated in many lines. The most frequent of these are staining of the stipules at the base of the emerging leaf and staining of the flowers at the base of the carpels and siliques (especially the nectaries). Because these staining patterns appear at high frequencies, often in conjunction with specific staining of different organs or tissues within the same plant, it is not clear whether these patterns represent true gene expression patterns. The GUS staining patterns listed under separate headings in Table 2 appear to be restricted to the organ or tissue specified, but a complete study of the lines for all tissues and developmental stages has not been made. In this survey they represent $<50 \%$ of the GUS-expressing transposant lines. The remainder of the lines showed GUS-staining in more than 


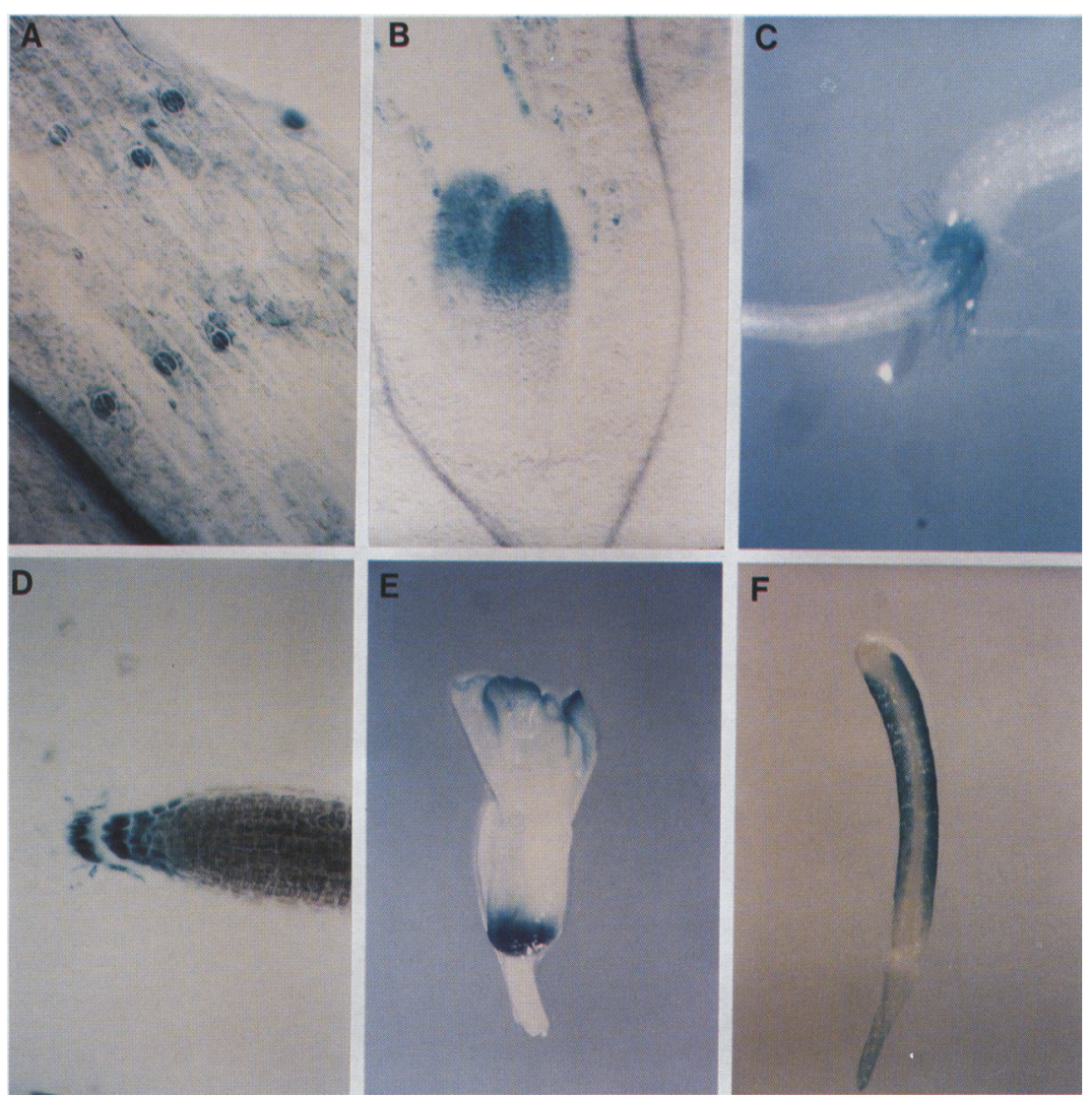

Figure 6. GUS expression patterns in transposant lines carrying enhancer trap insertions (ETs). (A) Staining in the hypocotyl (ET206); $(B)$ staining in the distal region of the leaf primordia (ET220); $(C)$ staining in mature root hairs near the collet (ET58); $(D)$ staining in the root cap (ET51); $(E)$ Staining in the petals of the flower (ET195); $\langle F\rangle$ staining in the carpel walls (ET153). one organ or tissue. Staining patterns in which GUS expression occurs in different organs or at different developmental stages within the same plant could be attributable to the existence of common or similar cell types in different organs or to expression of the same gene in different developmental programs (see Discussion).

A separate screen for mutant phenotypes was also conducted, and a summary of these is included in Table 3. The insertion lines segregating these mutations were stained for GUS activity in the heterozygotes. In twothirds of the enhancer trap insertions and one-third of the gene trap insertions, GUS staining was observed. The staining patterns were generally consistent with the mutant phenotype in these cases. For example, seedling pigmentation mutants (albinos or pale greens) stained in the cotyledons or the leaf primordia. A female semisterile mutant called prolifera, generated as a GT transposant by the method described here, stained in the developing ovules, as well as in zones of cell division activity elsewhere in the plant (Springer et al. 1995). Characterization of the other mutants described in Table 3 requires detailed analysis, which is currently in progress.

\section{Discussion}

We have developed an efficient transposon-based system for the identification of plant genes by their patterns of expression in development. The system uses an immo- bilized $A c$ element as the source of transposase and $D s$ elements engineered to act as enhancer traps $(D s E)$ or as gene traps (DsG). Previously, Fedoroff and Smith (1993), and Klimyuk et al. (1995) have described the construction of an enhancer trap $D s$ element and discussed its potential use for detection of plant enhancers. Here we have successfully used an enhancer trap element, $D s E$, for the detection of different enhancers in plants. We have also adapted gene trap vectors to plants, which exploit splicing to generate reporter gene expression. As described in Results, both types of elements function efficiently to detect diverse patterns of gene expression.

To overcome limitations imposed by the preferential transposition of $A c / D s$ elements to closely linked sites, we have developed a novel selection scheme to enrich for unlinked transpositions of $D s$ elements. We have demonstrated that this selection scheme, in which we select for the transposed $D$ s element $\left(\operatorname{Kan}^{\mathrm{R}}\right)$ and select against the donor site and the $A c\left(\mathrm{NAM}^{\mathrm{R}}\right)$, works efficiently in practice (Figs. 2 and 3). Using both physical and genetic mapping to analyze transpositions from two donor loci, we confirmed that the transposed $D s$ elements examined were either unlinked or loosely linked to the donor locus (Fig. 5), supporting the validity of our method for the generation of random independent insertions across the Arabidopsis genome.

T-DNA insertion vectors designed to act as promoter traps, wherein reporter gene expression depends on 
Figure 7. GUS expression patterns in transposant lines carrying gene trap insertions (GTs). (A) Staining within the shoot apex (GT185); $(B)$ staining in leaf primordia (GT257); $(C)$ staining of young trichomes $(G T 70) ;(D)$ staining of the filaments of the stamens (GT56); $(E)$ staining of the carpels (GT142); (F) staining of the margin of the carpel walls (GT140).
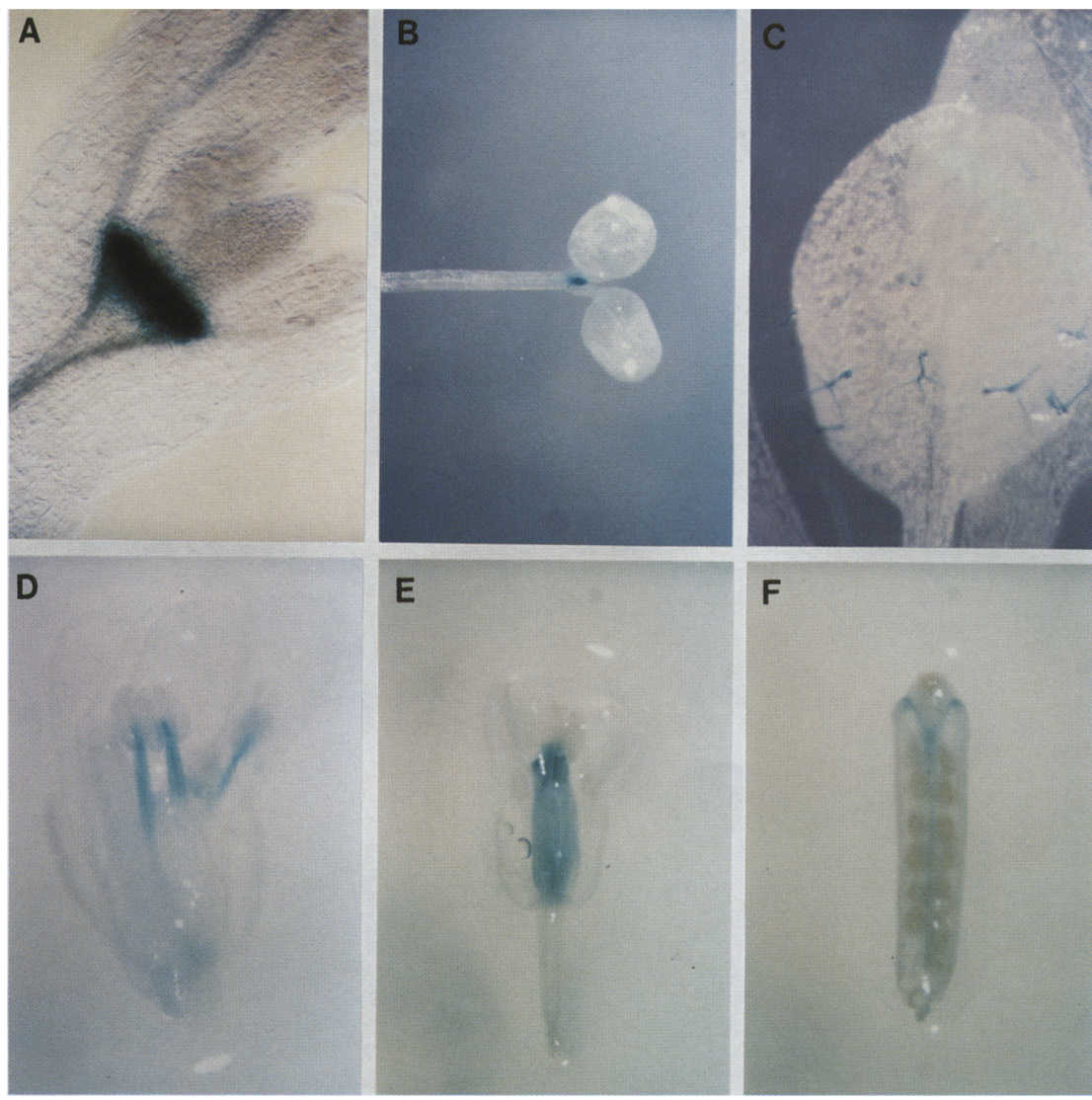

F readthrough transcription, have been used previously for gene detection and cloning in tobacco and Arabidopsis (Koncz et al. 1989; Kertbundit et al. 1991; Topping et al. 1991). The transposon approach that we have used has several advantages over the T-DNA promoter trap inser-

Table 1. Staining patterns of transposants in Figures 6 and 7

\begin{tabular}{|c|c|c|}
\hline $\begin{array}{l}\text { Figure } \\
\text { no. }\end{array}$ & $\begin{array}{l}\text { Transposant } \\
\text { no. }\end{array}$ & Description of staining pattern \\
\hline $6 \mathrm{~A}$ & ET206 & $\begin{array}{l}\text { hypocotyl: guard cells, vasculature; } \\
\text { shoot meristem }\end{array}$ \\
\hline $6 \mathrm{~B}$ & ET220 & $\begin{array}{l}\text { leaf: distal half of leaf primordia, } \\
\text { entire mature leaf }\end{array}$ \\
\hline $6 C$ & ET58 & root: root hairs \\
\hline $6 \mathrm{D}$ & ET51 & root: root caps \\
\hline $6 \mathrm{E}$ & ET195 & $\begin{array}{l}\text { flower: petals, strong staining near } \\
\text { the tips }\end{array}$ \\
\hline $6 \mathrm{~F}$ & ET153 & $\begin{array}{l}\text { flower: carpel walls excluding } \\
\text { margins }\end{array}$ \\
\hline $7 \mathrm{~A}$ & GT185 & shoot apex: band of cells \\
\hline $7 \mathrm{~B}$ & GT257 & leaf: leaf primordia \\
\hline $7 \mathrm{C}$ & GT70 & leaf: proximal trichomes \\
\hline $7 \mathrm{D}$ & GT56 & $\begin{array}{l}\text { flower: filaments of stamens; } \\
\text { hypocotyl: vasculature; cotyledons }\end{array}$ \\
\hline $7 E$ & GT142 & flower: carpels \\
\hline $7 F$ & GT140 & flower: margins of carpel walls \\
\hline
\end{tabular}

tion methods. First, the generation of large numbers of new insertions using transposons is accomplished simply by crossing a small number of plants and a subsequent one-step plate selection. Second, the insertions generated by $D s$ transposition are single copies of the intact element, reducing the possibility of artifactual patterns of reporter gene expression arising from multiple tandem or rearranged insertions. Third, the simple structure of $D s$ insertions makes the amplification of flanking DNA sequences by IPCR a relatively straightforward procedure. Finally, $D$ s insertions can be remobilized by crossing in $A c$, a feature that can be exploited to generate revertants to easily confirm that a gene has been tagged, as well as to generate allelic series and somatic mosaics for more detailed studies of gene function.

\section{Frequencies of insertion into or near expressed genes}

The fraction of transposants that stained for GUS expression in seedlings, leaves, or flowers was $\sim 26 \%$ for the gene trap DsG element and $48 \%$ for the enhancer trap $D s E$ element. The higher frequency of staining obtained with $D s E$ is to be expected. Because enhancers can act at long distances, DSE insertions into the transcribed and nontranscribed regions of genes, in either orientation, can result in GUS expression. On the other hand, $D s G$ insertions into genes will result in GUS expression only when inserted within the transcribed region and in the 
Table 2. Summary of GUS expression patterns

\begin{tabular}{|c|c|c|c|c|c|c|c|c|c|}
\hline & \multirow{2}{*}{$\begin{array}{l}\text { No. } \\
\text { screened }\end{array}$} & \multirow{2}{*}{$\begin{array}{l}\text { GUS } \\
\text { stain }^{a} \\
|\%|\end{array}$} & \multicolumn{6}{|c|}{$\begin{array}{c}\text { Staining restricted to } \\
\qquad \% \mid\end{array}$} & \multirow[b]{2}{*}{ Total } \\
\hline & & & root & hyp & $\cot$ & SA & leaf & flo & \\
\hline ET & 214 & 48 & 7 & 1 & 4 & 1.5 & 2 & 3.5 & 19 \\
\hline GT & 246 & 26 & 4 & 1 & 2.5 & 0.5 & 1 & 3 & 12 \\
\hline
\end{tabular}

aPercentage of lines showing GUS expression in seedlings and/or flowers. Lines with ubiquitous GUS expression are not included.

${ }^{b}$ Lines displaying GUS staining restricted to the following organs or tissues: (hyp) hypocotyl; (cot) cotyledons; (SA) shoot apex $;$ (flo) flower.

correct orientation. Gene trap vectors have several advantages that can compensate for the decreased efficiency of gene detection, for example, simplified isolation of CDNA probes by RACE-PCR (rapid amplification of cDNA ends-PCR) (Skarnes 1990; Springer et al. 1995).

$\bar{T}$ he GÜS staining patterns observed in the transposants reflect the diversity of gene expression patterns and cell types in plants. The same gene can be expressed in different developmental programs, as indicated by transposants such as GT56 (expression in the filaments of the stamens and in the cotyledons of the seedling). A high fraction of the lines with expression patterns showed expression in multiple organs or developmental stages $160 \%$ for the enhancer traps and $55 \%$ for the gene traps; see Table 2), suggesting that many genes in Arabidopsis are turned on and off as required during development. Examples of the repeated use of the same gene products in different developmental programs are common in animal systems, for example, the hedgehog and wingless genes in Drosophila. In some cases, however, the staining of a multiplicity of organs or tissues in a single insertion line can be explained simply by the occurrence of common cell types or activities. For example, there were several transposants in which staining of all green tissues was observed, including the hypocotyl, cotyledons, leaves, sepals, and carpels, suggesting insertions into genes associated with photosynthesis. Similarly, some transposant lines exhibit GUS staining in shoot and root meristems, as well as leaf primordia, indicative of genes expressed during cell division. One such transposant, GT148, was analyzed molecularly and found to carry an insertion into a homolog of a yeast cell division cycle gene (Springer et al. 1995).

The frequency of new mutations observed in the transposant lines is $\sim 4 \%$ (Table 3 ), which is consistent with previous observations using $A c / D s$ systems in Arabidopsis (Bancroft et al. 1993; Long et al. 1993); at least half of these are expected to be tagged with $D s$ insertions (Bancroft et al. 1993; C. Dean, unpubl.). This frequency for new mutations is significantly lower than the frequency of transposant lines that stain for GUS $148 \%$ for the ET lines, and $26 \%$ for the GT lines; Table 2). The screen for mutations in Table 3 included only seedling and floral phenotypes. A screen for some other types of visible mutations, such as embryo lethals, is currently in progress and is likely to result in a higher estimate for the frequency of mutations. Nevertheless, the available data suggest that the frequency of mutant phenotypes may be low relative to frequency of expression patterns. There are a number of plausible explanations for this difference in frequencies. First, many of the insertions may result in GUS expression without gene disruption. For example, DsE insertions into sequences upstream of a chromosomal gene can result in reporter gene expression without seriously affecting the expression of the chromosomal gene. Such an explanation is less likely for the gene trap transposants, but it is possible that a DsG insertion into an intron of a gene may not disrupt splicing completely, allowing sufficient gene expression to suppress a mutant phenotype. In such cases, it should be possible to remobilize the $D s$ element using $A c$ and generate secondary transpositions that result in null mutations. Second, some of the gene disruptions may have phenotypes that are subtle and were therefore missed in our visual screen, or they may have phenotypes that are only obvious under abnormal conditions (e.g., responses to cold or heat shock, or to pathogen infection). In these cases, the expression pattern can be used to direct a more detailed examination for phenotypes. It may also be possible to predict the function of the gene and the phenotypic consequences of gene disruption, from sequence information obtained using amplification by IPCR or RACE-PCR.

Finally, many of the genes in Arabidopsis may be

Table 3. Screen for visible mutations in the seedlings and flowers

\begin{tabular}{|c|c|c|c|c|c|c|c|c|}
\hline & \multirow{2}{*}{$\begin{array}{l}\text { No. } \\
\text { screened }\end{array}$} & \multicolumn{5}{|c|}{ Mutant phenotypes ${ }^{\mathrm{a}}$} & \multirow[b]{2}{*}{ Total } & \multirow{2}{*}{$\begin{array}{l}\text { GUS } \\
\text { stain }\end{array}$} \\
\hline & & SP & SM & FM & MS & $\overline{\text { FS }}$ & & \\
\hline ET & 214 & 3 & 2 & 2 & 1 & 0 & 8 & 6 \\
\hline GT & 246 & 6 & 0 & 1 & 2 & 1 & 10 & 3 \\
\hline
\end{tabular}

${ }^{a}$ Mutant phenotypes were scored by visual inspection of seedlings and flowers. (SP) Seedling pigmentation; (SM) seedling morphology; (FM) floral morphology; (MS) male sterile; (FS) female semisterile. 
functionally redundant. In studies of the budding yeast $S$. cerevisiae, $60 \%-70 \%$ of gene disruptions have no discernible phenotype (Goebl and Petes 1986; Oliver et al. 1992; Burns et al. 1994). Our study suggests that a similar or greater redundancy may be present in the more complex genome of Arabidopsis. If so, a large fraction of the genes expressed in Arabidopsis will not be identified in standard genetic screens for mutant phenotypes, and approaches such as the gene trap/enhancer trap transposon system described here may prove particularly important for the identification and characterization of these expressed genes.

\section{Developmental markers and identification of cell types}

The transposon insertions generated in this study should be useful not only for the identification and cloning of developmentally regulated genes (Springer et al. 1995) but also as a source of markers that define different developmental stages or cell types. Such cell- or tissuespecific markers can be valuable in the study of normal development, as well as in assessing the effects of regulatory mutations (Wilson et al. 1990; Wagner-Bernholz et al. 1991; Grossniklaus et al. 1992; Affolter et al. 1994). In the insertions shown in Figures 6 and 7, and described in Table 1 and Results (under Screening for expression patterns), examples of such markers are described. The insertion in ET220 (Fig. 6B) is an early differentiation marker for leaf maturation, as it stains the distal (older) half of the leaf primordia and also stains mature leaf uniformly, but not other green tissues such as the cotyledons and hypocotyl. GT70 (Fig. 7C) is similarly a marker for early trichome development, as it stains young trichomes strongly and older trichomes weakly or not at all. ET58 (Fig. 6C) provides a developmental marker for root hairs. ET51 (Fig. 6D) is a marker for root cap differentiation, as it stains root caps of primary as well as lateral roots, but not the lateral root primordia. Lines similar to GT257 (Fig. 7B) provide developmental markers for distinguishing between leaves and cotyledons, despite the many common cell types in the two organs. ET195 (Fig. 6E), ET153 (Fig. 6F), GT56 (Fig. 7D), GT142 (Fig. 7E), and GT140 (Fig. 7F) provide markers for different organs or parts of organs within flowers. ET195 (Fig. 6E) provides a petal-specific marker, and GT56 (Fig. 7D) provides a marker for the filaments of the stamens. Whereas GT142 (Fig. 7E) is a marker that stains the entire carpel, GT140 (Fig. 7F) stains only the margin of fusion of the carpels and ET153 (Fig. 6F) stains the carpel wall excluding this margin. The existence of a different cell type at this margin is predicted from scanning electron microscopy (Bowman 1994) and is confirmed here from the GUS expression patterns of GT 140 and ET 153. Such insertions can be used as cell-specific and organspecific markers for characterization of the large collection of floral homeotic mutants in Arabidopsis.

In the expression patterns of some insertions, unexpected differences between cell types were observed. For example, the transposant ET206 showed GUS expression in the guard cells of the hypocotyl (Fig. 6A) but not in the guard cells of the cotyledons or the leaf. This observation suggests that the position of a guard cell within the plant affects its gene expression pattern and, perhaps, reflects functional differences between guard cells in the hypocotyl and those in leaves and cotyledons that are not obvious from microscopic observations. The expression pattern observed in transposant GT185 defines a distinct band of cells within the shoot apex (Fig. 7A). From detailed miscroscopic and histological studies of meristems in higher plants, differences between the cells constituting the meristem have been described for cells in the layers that will later give rise to the epidermis and the subepidermal and ground tissues and for cells that are at the sites of initiation of organ primordia (Steeves and Sussex 1989). Spatially restricted patterns of expression in the vegetative shoot meristem have been observed in molecular studies of cloned genes, indicative of other differences between the cells in the meristem (Medford et al. 1991; Fleming et al. 1993; Jackson et al. 1994; Lincoln et al. 1994). In this case, the gene trap insertion GT185 suggests the existence of a distinct domain of cells within the shoot apex, defined by this novel expression pattern, that was not revealed by previous microscopic and histological studies.

The identification of different cell types in plants traditionally has been made on the basis of differences in cell morphology or cell physiology. In general, such differences are expected to reflect differences in the expression of specific cellular genes. For example, petal cells and sepal cells are distinguished easily in most cases by their cell shapes and pigment synthesis (Bowman 1994). These differences are reflected in the expression of different sets of genes in the two cell types, including different expression of floral homeotic genes. However, a difference in the gene expression pattern between two cells need not result in visible or easily measured differences in cell morphology or physiology. In particular, subtypes of cells sharing similar morphology, but differing in their expression of specific genes, can have distinct functions. The identification of subtypes has proven important to the understanding of many biological processes (e.g., in the immune system). Cell-specific expression patterns, detected using transposon insertions, can provide a new approach for the identification of cell types or subtypes of cells in higher plants.

\section{Conclusions}

We have introduced gene trap and enhancer trap transposons into Arabidopsis and used them to generate a collection of insertions with diverse patterns of reporter gene expression. These transposon insertions can be used for the identification and characterization of genes that are expressed in different developmental processes. The insertion lines also provide specific markers for different tissues, organs, and cell types that should be valuable for characterizing the effects of regulatory mutations, and for identification of novel cell types and subtypes in higher plants. Because new insertions can be obtained by a simple crossing and one-step plate selec- 
tion procedure, generation of sufficiently large numbers of insertions to approach genome saturation should be feasible; this effort is currently in progress.

\section{Materials and methods}

\section{Construction of the transposable elements}

Figure 8 shows a detailed sketch of the $A c$ and $D s$ elements used in this study and their location relative to the selectable marker genes within the T-DNA. As stated earlier, the $A c$ element used (Fig. 8A) is the $35 \mathrm{~S}-A c$ transposase fusion constructed by Scofield et al. (1993). Two types of $D s$ elements were constructed for this study.

Enhancer trap element DsE The enhancer trap $D$ s element $D s E$ is shown in Figure 8B. DsE is designed so that expression of the reporter gene is dependent on its insertion near chromosomal enhancer sequences. The sequences from 1785 to 4344 of the 4565-bp-long Ac element, which have been demonstrated previously to be nonessential for transposition (Coupland et al. 1989), have been replaced by a GUS reporter gene and a NPTII

A

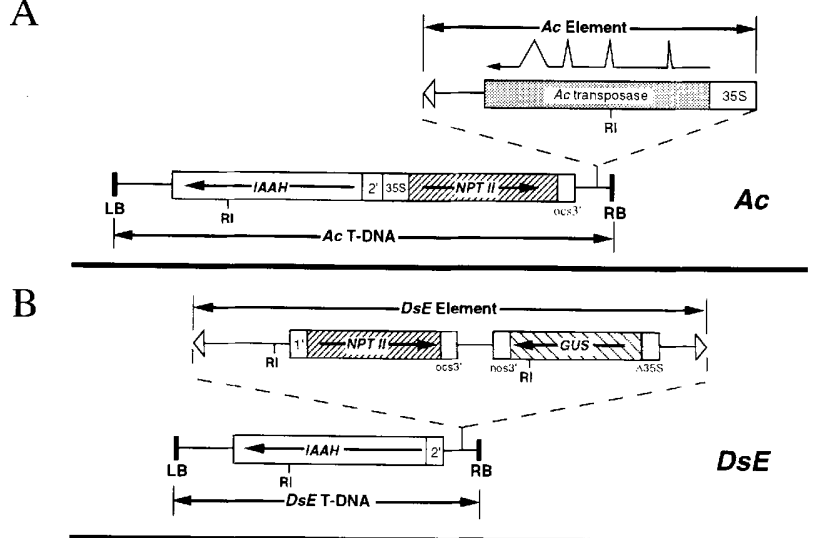

$\mathrm{C}$

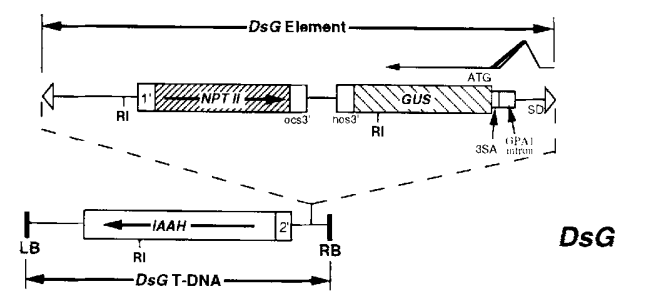

$\mathrm{D}$

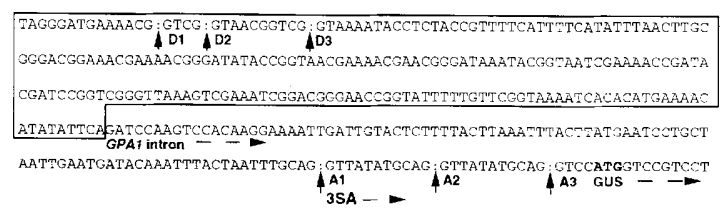

Figure 8. Details of constructs and T-DNA vectors used in this study. $(A)$ Immobilized $A c$ element; $(B)$ enhancer trap element $D s E_{;}(C)$ gene trap element $D s G ;(D) D s G$ terminal sequences showing positions of splice donors $(\mathrm{D} 1, \mathrm{D} 2, \mathrm{D} 3)$ and splice acceptors (A1, A2, A3). (NPTII) Neomycin phosphotrans-

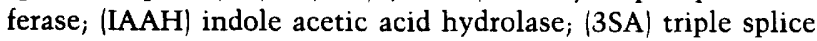
acceptor; (GPA1) gene for G-protein $\alpha$-subunit from Arabidopsis; (LB and RB) left border and right border sequences, respectively, of the T-DNA. selectable marker gene, as detailed below. The GUS reporter gene is fused to a minimal promoter derived from the -1 to -46 region of the $35 \mathrm{~S}$ promoter of CaMV. This region, which includes the TATA box, has been shown to have no promoter activity in the absence of enhancer sequences (Benfey et al. 1989). The minimal promoter of the GUS gene is $230 \mathrm{bp}$ from the $3^{\prime}$ ' end of the element /defined by the direction of $A C$ transcription).

The NPTII gene, which confers resistance to kanamycin, is in the opposite orientation to the GUS gene and is driven by the $1^{\prime}$ promoter taken from the T-R region of T-DNA (Velten et al. 1984).

Gene trap element DsG The gene trap $D s$ element, $D s G$, is shown in Figure 8C and is designed to detect the expression of genes when the element is inserted within a transcribed region. As with DsE, the internal sequences from 1785 to 4344 of the $A c$ element have been replaced by a GUS reporter gene and a $1^{\prime}$-NPTII fusion. However, instead of the minimal promoterGUS fusion used in $D s E, D s G$ contains an intact but promoterless GUS gene, with an intron fused upstream of the GUS ATG codon. The intron used is the 91 -nucleotide fourth intron of the Arabidopsis G-protein gene GPA1 (Ma et al. 1990). Two additional consensus splice acceptor sequences have been added using an oligonucleotide called 3SA (Fig. 8C), so that there is a splice acceptor in every reading frame. If the $D s G$ element transposes into the intron of a chromosomal gene, with the GUS gene in the correct orientation, we expect to get splicing from the splice donor of the chromosomal intron to the splice acceptors in front of the GUS gene.

To ensure that a gene trap vector used in plants will function when inserted into exons, as well as into introns, we have exploited the existence of splice donors at one end of the $D s$ element (Wessler et al. 1987, 1988). Three splice donor sites that have been identified are at 14,24 , and 28 bp from the $3^{\prime}$ end of the $D s$ element, and they cover all three potential reading frames (Wessler et al. 1987, 1988, 1991; see Fig. 8D). If DsG inserts into an exon, the sequence between the splice donor sites at the end of the element and the splice acceptors introduced in front of the GUS gene ( 300 nucleotides), will be spliced out from the transcript. There are, however, two stop codons at 1 and $7 \mathrm{bp}$ from the end of the element, which cannot be spliced out because the first splice donor sequence is at $14 \mathrm{bp}$ from the end (Fig. 8D; Wessler et al. 1987, 1988). These stop codons will not affect insertions into noncoding exons but will affect a fraction of the insertions of the DsG element into coding exons, unless there is significant reinitiation at the ATG of the GUS gene. The utilization of these splice donors and acceptors in vivo has been studied by analyzing RNA from transgenic Arabidopsis plants in which the DsG element was cloned downstream of the 35S promoter (Nussaume et al. 1995). For each possible reading frame, at least one combination of the splice acceptors and donors could be found that would be capable of generating an in-frame fusion, if inserted into a coding exon. We have also obtained confirmation that the splice acceptors are utilized in vivo to generate GUS transcriptional fusions, by sequence analysis of cDNA from plants carrying an insertion of $D s G$ into an intron of the prolifera gene (Springer et al. 1995).

\section{Construction of starter lines}

The $A c$ and $D s$ elements were subcloned into T-DNA vectors for Agrobacterium-mediated transformation of Arabidopsis. The pRK290-based binary vector pSLJ491 (Jones et al. 1992) was first modified by introducing within the T-DNA borders a fu- 
sion of the IAAH gene to the 2' promoter (Bancroft et al. 1992). The IAAH gene confers sensitivity of the plants to NAM, by conversion of NAM to NAA, which is a potent auxin (KarlinNeumann et al. 1991). The $D$ s elements were cloned separately into a SacI site adjacent to the IAAH gene of this modified binary vector (Fig. $8 \mathrm{~B}, \mathrm{C}$ ). The $2^{\prime}$-IAAH fusion was also introduced into pSLJ1111 (Scofield et al. 1993), a pRK290-based binary vector containing both the immobilized $35 \mathrm{~S}-A c$ element, and the 1'-NPTII fusion (Fig. 8A).

The T-DNA binary vectors carrying $D s G, D s E$, and $35 \mathrm{~S}-A c$ were conjugated into Agrobacterium tumefaciens strain C58 and used for transformation of Arabidopsis Landsberg erecta plants by the root transformation protocol of Valvekens et al. (1988), with modifications described in Huang and $\mathrm{Ma}$ (1992). Transformants were selected by virtue of the $\operatorname{Kan}^{\mathrm{R}}$ conferred by the 1'-NPTII fusion. Several independent transformants were obtained for each element, and these were characterized by Southern blotting to determine the number of T-DNA insertions (not shown). Plants with single T-DNA insertions were propagated, and homozygotes were identified genetically by segregation of $\mathrm{Kan}^{\mathrm{R}}$, and used as the starter lines in the crosses described below. In this initial study, three $A C$ starter lines (called Ac1, Ac2, Ac5), three DsE starter lines (DsE1, DsE2, DsE3), and one DsG starter line (DsG1) have been used.

\section{Mobilization of the Ds elements}

For mobilization of the $D s E$ element, crosses were performed between plants from the Ac1, Ac2 and Ac3 lines to plants from the DsE1, DsE2 and DsE3 lines in all combinations. A total of $590 \mathrm{Fl}$ seeds from these crosses, containing approximately equal numbers of seed from each combination, were planted on soil and allowed to self. Approximately 1000-2000 seeds were collected from each Fl plant. For mobilization of the DsG element, plants from the DsGl line were crossed to plants from the Acl line. Fl seeds (733) from these crosses were planted and allowed to self; and 1000-2000 seeds were collected from each plant.

\section{Selection for $\operatorname{Kan}^{R} N A M^{R}$ transposants}

Approximately $1000 \mathrm{~F} 2$ seeds $(20 \mathrm{mg}$ ) from each F1 plant are sterilized in a $15-\mathrm{ml}$ conical tube by successive washes with 1-2 $\mathrm{ml}$ of $95 \%$ ethanol for $5-10 \mathrm{~min}$ and $1 \mathrm{ml}$ of bleach solution (containing 1\% sodium hypochlorite, and $0.1 \%$ Tween 20 ) for 5-10 min, and three times with $10 \mathrm{ml}$ of sterile water. The seeds are then suspended in $8 \mathrm{ml}$ of top agar containing selective medium (see below), and plated onto $150 \times 25-\mathrm{mm}$ selection plates containing $0.44 \%$ MS salts (Sigma), adjusted to $\mathrm{pH} 5.7$ with $\mathrm{KOH}, 1 \%$ sucrose, $0.7 \%$ agar, $50 \mu \mathrm{g} / \mathrm{ml}$ of kanamycin, and $3.5 \mu$ M NAM (Sigma). After 4 days at $4^{\circ} \mathrm{C}$, the plates are placed in a growth chamber for 3-5 days. Seedlings resistant to both NAM and kanamycin are recognized by their normal size, root development, and green color (Fig. 2B,C). They are transferred to small $(60-\mathrm{mm})$ selection plates to verify the phenotype. After they reach the two-leaf stage, they are transferred to soil and allowed to self, and the seeds (the F3 generation) are harvested and stored as a transposant line. To ensure a collection of independent insertions, it is necessary to propagate a single $\mathrm{Kan}^{\mathrm{R}}$. $\mathrm{NAM}^{\mathrm{R}}$ plant from each $\mathrm{F} 2$ family (see Results). F2 families (590) obtained from crosses of starter lines carrying $D s E$ and $A c$ were plated on selective media containing kanamycin and NAM, to generate 225 independent transposant lines. Similar results were obtained with crosses of $D s G$ to $A c: 266$ independent transposant lines were generated from 733 F2 families. Enhancer trap transposant lines generated in this study are num- bered ET1 through ET225, and gene trap transposant lines are numbered GT1 through GT266.

\section{Staining for GUS expression}

F3 (15 to 20) seeds from each transposant line are sterilized and germinated on plates, or germinated on soil without sterilization. Whole seedlings from the plates, or inflorescences from soil-grown plants are transferred into microtiter wells containing $500 \mu \mathrm{l}$ of GUS staining solution [100 mM Na Phosphate at $\mathrm{pH} 7,10 \mathrm{~mm}$ EDTA, $0.1 \%$ Triton X-100, $1 \mathrm{mg} / \mathrm{ml}$ of X-Gluc (Biosynth AG), $100 \mu \mathrm{g} / \mathrm{ml}$ of chloramphenicol to inhibit bacterial growth]. The specificity of localization was improved in most cases by including $1 \mathrm{~mm}$ potassium ferricyanide and $1 \mathrm{~mm}$ potassium ferrocyanide (Jefferson 1987), but for transposants with weak expression, GUS staining was only visible in the absence of ferricyanide and ferrocyanide. The microtiter dish is placed under vacuum for $10 \mathrm{~min}$ in a dessicator. After release of the vacuum, the dish is covered with foil and incubated at $37^{\circ} \mathrm{C}$ overnight. The stain solution is removed, and the tissues are cleared by incubation with several changes of $70 \%$ ethanol at $37^{\circ} \mathrm{C}$.

\section{Mapping of Ds elements}

Probes for mapping the elements were generated using IPCR to amplify the flanking chromosomal DNA. For mapping the $D s G$ element in the DsGl starter line, IPCR was performed using primers to the right border of the T-DNA. DNA from the DsGl starter line was digested with TaqI, ligated under dilute conditions to permit circularization, and then amplified using the primers TRO and TRI, whose sequences are as follows: TRO, GCTCTAGAGCGAATTTGGCCTGTAGA; and TRI, CGGGATCCATCGTAGGTGAAGGTGGAAA. The product of this amplification was reamplified, using TRI and the nested primer B50, which is internal to TRO. The sequence of B50 is TCTAATTTCAAACTATTCGGGCCTAAC. For the transposed $D S G$ elements, primers to the ends of the Ds element were used. The primers used for the $5^{\prime}$ end of the element are Ds5O and Ds5I, for the initial amplification, and the nested primers Ds5O2 and Ds5I2 for the reamplification. Their sequences are as follows: Ds5O, GTTCGAATTCGATCGGGATAAAAC; Ds5I, GGTAGTCGACGAAAACGGAACGGAAAC; Ds5O2, AAATCAGATCTACGATAACGGTCGG; and Ds5I2, AAACGGTACCCGGAAACGGAAACGG. The primers for the 3' end of the element are Ds3O and Ds3I, for the initial amplification, and the nested primers Ds3O2 and Ds3I2 for the reamplification. Their sequences are as follows: Ds3O, AGTTAGATCTGAAAATGAAAACGGTAGAGG; Ds3I, CTTGGTCGACGGAAACGAAAACGGG; Ds3O2, CGACCGGTACCGACCGTTTTCATCC; and Ds3I2, TACCGGTACCGAAAACGAACGGGAT. The DNA from a transposant line carrying a transposed $D s G$ element was digested with $N d e I I$ or $B f a I$ which have sites near the $5^{\prime}$ end of the element, or with TaqI, which cuts near the 3 ' end of the element. After circularization, PCR amplification was performed using the 5 '-end primers for amplification of NdeII- and BfaI-digested DNA or 3 '-end primers for amplification of TaqI-digested DNA. In many cases, a product of useful size could not be obtained with any of the three enzymes used. IPCR was performed on 36 transposant lines using all three restriction enzymes, and probes could be generated for $24 D s G$ insertions.

To identify restriction polymorphisms, the final PCR products were gel-purified and used in labeling reactions to probe Southern blots containing restriction digests of Arabidopsis DNA from the Landsberg and Columbia ecotypes. RFLPs for at 
least 1 of 14 enzymes tested could be identified for five of the IPCR probes. These probes were then hybridized to Southern blots of restriction enzyme-digested DNA from 75 recombinant inbred lines generated from the Landsberg erect $a$ and Columbia ecotypes (Lister and Dean 1993). The segregation data were analyzed by Dr. Clare Lister at the John Innes Centre (UK), using Mapmaker v. 1.0 to determine the map position of the probe on the current RI map of Arabidopsis (Lister and Dean 1993).

The genetic distances of transposed $D s$ elements relative to the donor loci were estimated as follows. Plants carrying transposed $D s$ elements were backcrossed to the starter $D s$ line, and the progeny were selfed. About 1000 seeds from each self were germinated on kanamycin, and the fraction of $\mathrm{Kan}^{\mathrm{s}}$ seedlings in this population was calculated. If the transposed $D s$ element is unlinked to the donor $D s$, then approximately one-sixteenth of the seedlings should be Kan ${ }^{\mathrm{s}}$. This ratio of one-sixteenth $\mathrm{Kan}^{\mathrm{s}}$ progeny was found for three of the four transposed $D$ s elements. The fourth transposed Ds was linked to the donor DsE element, as the fraction of $\operatorname{Kan}^{\mathrm{S}}$ progeny was only $1 / 128$, so that the estimated genetic distance of this transposed $D s$ from the donor site is $18 \mathrm{cM}$.

\section{Acknowledgments}

We thank A. Baron, E. Chan, L. Das, Y. Hu, A. Tagle, P. Weinberg, and Z. Yuan for technical assistance; C. Lister for the RI analysis; J. Ecker for the YAC library; S. Woody for helpful advice; U. Grossniklaus, W. Herr, and G. Ruvkun for critical comments on the manuscript; $T$. Mulligan for care of the plants; and S. Arana for preparation of the manuscript. The research was supported by the Robertson Research Fund, a National Science Foundation (NSF) grant (MCB-9408042) to R.M. and V.S., and an NSF postdoctoral fellowship (BIR-9303612) to P.S. This paper is dedicated to the memory of Barbara McClintock, whose discovery of transposable elements and research on the $A c-D s$ system made this work possible.

The publication costs of this article were defrayed in part by payment of page charges. This article must therefore be hereby marked "advertisement" in accordance with 18 USC section 1734 solely to indicate this fact.

\section{References}

Aarts, M.G.M., W.M. Dirkse, W.J. Stiekema, and A. Pereira. 1993. Transposon tagging of a male sterility gene in Arabidopsis. Nature 363: 715-717.

Affolter, M., J. Montagne, U. Walldorf, J. Groppe, U. Kloter, M. LaRosa, and W.J. Gehring. 1994. The Drosophila SRF homolog is expressed in a subset of tracheal cells and maps within a genomic region required for tracheal development. Development 120: 743-753.

Bancroft, I. and C. Dean. 1993. Transposition pattern of the maize element $D s$ in Arabidopsis thaliana. Genetics 134: 1221-1229.

Bancroft, I., A.M. Bhatt, C. Sjodin, S. Scofield, J.D.G. Jones, and C. Dean. 1992. Development of an efficient two-element transposon tagging system in Arabidopsis thaliana. Mol. \& Gen. Genet. 233: 449-461.

Bancroft, I., J.D.G. Jones, and C. Dean. 1993. Heterologous transposon tagging of the DRL1 locus in Arabidopsis. The Plant Cell 5: 631-638.

Bellen, H.J., C.J. O'Kane, C. Wilson, U. Grossniklaus, R.K. Pearson, and W.J. Gehring. 1989. P-element-mediated enhancer detection:a versatile method to study development in Drosophila. Genes \& Dev. 3: 1288-1300.
Bier, E., H. Vaessin, S. Shepard, K. Lee, K. McCall, S. Barbel, L. Ackerman, R. Carretto, T. Uemera, E. Grell, L.Y. Jan, and Y.N. Jan. 1989. Searching for pattern and mutation in the Drosophila genome with a P-lacz vector. Genes \& Dev. 3: 273-1287.

Benfey, P.N., L. Ren, and N.H. Chua. 1989. The CaMV $35 S$ enhancer contains at least two domains which can confer different developmental and tissue-specific expression patterns. EMBO J. 8: 2195-2202.

Bowman, J. 1994. Arabidopsis: An atlas of morphology and development. Springer-Verlag, New York.

Burns, N., B. Grimwade, P.B. Ross-Macdonald, E.-Y. Choi, K. Finberg, G.S. Roeder, and M. Snyder. 1994. Large-scale analysis of gene expression, protein localization, and gene disruption in Saccharomyces cerevisiae. Genes \& Dev. 8: $1087-1105$.

Coupland, G., C. Plum, S. Chatterjee, A. Post, and P. Starlinger. 1989. Sequences near the termini are required for transposition of the maize transposon Ac in transgenic tobacco plants. Proc. Natl. Acad. Sci. 86: 9385.

Dooner, H.K. and A. Belachew. 1989. Transposition pattern of the maize element $A c$ from the $b z-m 2(A c)$ allele. Genetics 122: $447-457$.

Fedoroff, N. V. and D.L. Smith. 1993. A versatile system for detecting transposition in Arabidopsis. Plant I. 3: 273-289.

Fleming, A.J., T. Mandel, I. Roth, and C. Kuhlemeier. 1993. The patterns of gene expression in the tomato shoot apical meristem. The Plant Cell 5: 297-309.

Friedrich, G. and P. Soriano. 1991. Promoter traps in embryonic stem cells: A genetic screen to identify and mutate developmental genes in mice. Genes \& Dev. 5: 1513-1523.

Goebl, M.G. and T.D. Petes. 1986. Most of the yeast genomic sequences are not essential for cell growth and division. Cell 46: 983-992.

Gossler, A., A.L. Joyner, J. Rossant, and W.C. Skarnes. 1989. Mouse embryonic stem cells and reporter constructs to detect developmentally regulated genes. Science 244: 463-465.

Grossniklaus, U., R.K. Pearson, and W.J. Gehring. 1992. The Drosophila sloppy paired locus encodes two proteins involved in segmentation that show homology to mammalian transcription factors. Genes \& Dev. 6: 1030-1051.

Guzman, P. and J.R. Ecker. 1988. Development of large DNA methods for plants: molecular cloning of large segments of Arabidopsis and carrot DNA into yeast. Nucleic Acids Research 16: 11091-11105.

Huang, H. and H. Ma. 1992. An improved procedure for transforming Arabidopsis thaliana (Landsberg erecta) root explant. Plant Mol. Biol. Rep. 10: 372-383.

Jackson, D., B. Veit, and S. Hake. 1994. Expression of maize KNOTTED1 related homeobox genes in the shoot apical meristem predicts patterns of morphogenesis in the vegetative shoot. Development 120: 405-413.

Jefferson, R.A. 1987. Assaying chimeric genes in plants: The GUS gene fusion system. Plant Mol. Biol. Rep. 5: 387-405.

Jones, J.D.G., F. Carland, E. Lim, E. Ralston, and H.K. Dooner. 1990. Preferential transposition of the maize element Activator to linked chromosomal locations in tobacco. The Plant Cell 2: 701-707.

Jones J.D.G., L. Shlumukov, F. Carland, J. English, and S. Scofield. 1992. Effective vectors for transformation, expression of heterologous genes, and assaying transposon excision in transgenic plants. Transgen. Res. 1: 285-287.

Karlin-Neumann, G.A., J. Brusslan, and E. Tobin. 1991. Phytochrome control of the tms2 gene in transgenic Arabidopsis: A strategy for selecting mutants in the signal transduction pathway. The Plant Cell 3: 573-582. 
Kavanagh, T.A., R.A. Jefferson, and M.W. Bevan. 1988. Targeting a foreign protein to chloroplasts using fusions to the transit peptide of a chlorophyll a/b protein. Mol. \& Gen. Genet. 215: 38-45.

Kerr, W.G., G.P. Nolan, A.T. Serafini, and L.A. Herzenberg. 1989. Transcriptionally defective retroviruses containing $l a c Z$ for the in situ detection of endogenous genes and developmentally regulated chromatin. Cold Spring Harbor Symp. Quant. Biol. 54: 767-776.

Kertbundit, S., H. DeGreve, F. Deboeck, M. van Montagu, and J.-P. Hernalsteens. 1991. In vivo random $\beta$-glucuronidase gene fusion in Arabidopsis thaliana. Proc. Natl. Acad. Sci. 88: $5212-5216$.

Klimyuk, V.I., L. Nussaume, K. Harrison, and J.D.G. Jones. 1995. Novel GUS expression patterns following transposition of an enhancer trap Ds element in Arabidopsis. Mol. \& Gen. Genet. (in press).

Koncz, C., N. Martini, R. Mayerhofer, Z. Koncz-Kalman, H. Korber, G.P. Redei, and J. Schell. 1989. High-frequency T-DNA-mediated gene tagging in plants. Proc. Natl. Acad. Sci. 86: 8467-8471.

Lincoln, C., J. Long, J. Yamaguchi, K. Serikawa, and S. Hake. 1994. A knotted1-like homeobox gene in Arabidopsis is expressed in the vegetative meristem and dramatically alters leaf morphology when overexpressed in transgenic plants. The Plant Cell 6: 1859-1876.

Lister, C. and C. Dean. 1993. Recombinant inbred lines for mapping RFLP and phenotypic markers in Arabidopsis. Plant J. 4: 745-750.

Long, D., M. Martin, E. Sundberg, J. Swinburne, P. Puangsomlee, and G. Coupland. 1993. The maize transposable element system $A c / D s$ as a mutagen in Arabidopsis. Proc. Natl. Acad. Sci. 90: 10370-10374.

Ma, H., M.F. Yanofsky, and E.M. Meyerowitz. 1990. Molecular cloning and characterization of GPA1, a G protein $\alpha$ subunit gene from Arabidopsis thaliana. Proc. Natl. Acad. Sci. 87: 382l-3825.

McClintock, B. 1950. The origin and behavior of mutable loci in maize. Proc. Natl. Acad. Sci. 6: 344-355.

Medford, J.I., J.S. Elmer, and H.J. Klee. 1991. Molecular cloning and characterization of genes expressed in shoot apical meristems. The Plant Cell 3: 359-370.

Mlodzik, M., Y. Hiromi, U. Weber, C.S. Goodman, and G.M. Rubin. 1990. The Drosophila seven up gene, a member of the steroid receptor gene superfamily, controls photoreceptor cell fates. Cell 60: 211-224.

Nussaume, L., K. Harrison, V. Klimyuk, R. Martienssen, V. Sundaresan, and J.D.G. Jones. 1995. Analysis of splice donor and acceptor sites function in a transposable gene trap derived from the maize element Activator. Mol. \& Gen. Genet. (in press).

O'Kane, C.J. and W.J. Gehring. 1987. Detection in situ of genomic regulatory elements in Drosophila. Proc. Natl. Acad. Sci. 85: 9123-9127.

Oliver, S.G., Q.J.M. van der Aart, M.L. Agostoni-Carbone, M. Aigle, L. Alberghina, D. Alexandraki, G. Antoine, R. Anwar, J.P.G. Ballesta, P. Benit et al. 1992. The complete DNA sequence of yeast chromosome III. Nature 357: 38-46.

Scofield, S.R., J.J. English, and J.D.G. Jones. 1993. High level expression of Activator transposase gene inhibits the excision of Dissociation in tobacco cotyledons. Cell 75: 507518.

Skarnes, W.C. 1990. Entrapment vectors: a new tool for mammalian genetics. BioTechnology 8: 827-831.

Springer, P.S., W.R. McCombie, V. Sundaresan, and R.A. Martienssen. 1995. Gene-trap tagging of PROLIFERA, an essen- tial MCM2-3-5-like gene in Arabidopsis. Science 268: 877880.

Steeves, T.A. and I.M. Sussex. 1989. Patterns in plant development, 2nd ed., Cambridge University Press, Cambridge, UK.

Swinburne, J., L. Balcells, S.R. Scofield, J.D.G. Jones, and G. Coupland. 1992. Elevated levels of $A c$ transposase mRNA are associated with high frequencies of $D s$ excision in Arabidopsis. The Plant Cell 4: 583-595.

Topping, J.F., W. Wei, and K. Lindsey. 1991. Functional tagging of regulatory elements in the plant genome. Development 112: 1009-1019.

Valvekens, D., M. Van Montagu, and M. Van Lijsebettens. 1988. Agrobacterium-mediated transformation of Arabidopsis root explants using Kanamycin selection. Proc. Natl. Acad. Sci. 85: 5536-5540.

Velten, J., L. Velten, R. Hain, and J. Schell. 1984. Isolation of a dual plant promoter fragment from the Ti plasmid of Agrobacterium tumefaciens. EMBO I. 3: 2723-2730.

Wagner-Bernholz, J.T., C. Wilson, G. Gibson, R. Schuh, and W.J. Gehring. 1991. Identification of target genes of the homeotic gene Antennapedia by enhancer detection. Genes \& Dev. 5: 2467-2480.

Wessler, S.R., G. Baran, and M. Varagona. 1987. The maize transposable element $D s$ is spliced from RNA. Science 237: 916-918.

-1988. Alterations in gene expression mediated by DNA insertions in the waxy gene of maize. In Plant transposable elements (ed. O.E. Nelson), pp. 293-303. Plenum Press, New York.

Wilson, C., R.K. Pearson, H.J. Bellen, C.J. O'Kane, U. Grossniklaus, and W.J. Gehring. 1989. P-element mediated enhancer detection: An efficient method for isolating and characterizing developmentally regulated genes in Drosophila. Genes \& Dev. 3: 1301-1313.

Wilson, C., H.J. Bellen, and W.J. Gehring. 1990. Position effects on eukaryotic gene expression. Annu. Rev. Cell Biol. 6: 679714. 


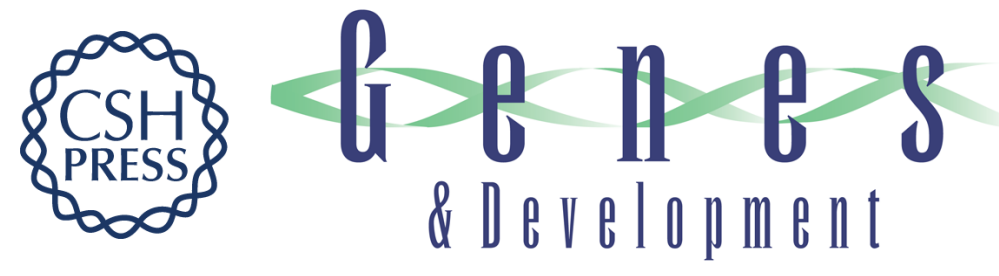

\section{Patterns of gene action in plant development revealed by enhancer trap and gene trap transposable elements.}

V Sundaresan, P Springer, T Volpe, et al.

Genes Dev. 1995, 9:

Access the most recent version at doi:10.1101/gad.9.14.1797

References This article cites 48 articles, 28 of which can be accessed free at:

http://genesdev.cshlp.org/content/9/14/1797.full.html\#ref-list-1

License

Email Alerting

Service

Receive free email alerts when new articles cite this article - sign up in the box at the top right corner of the article or click here.

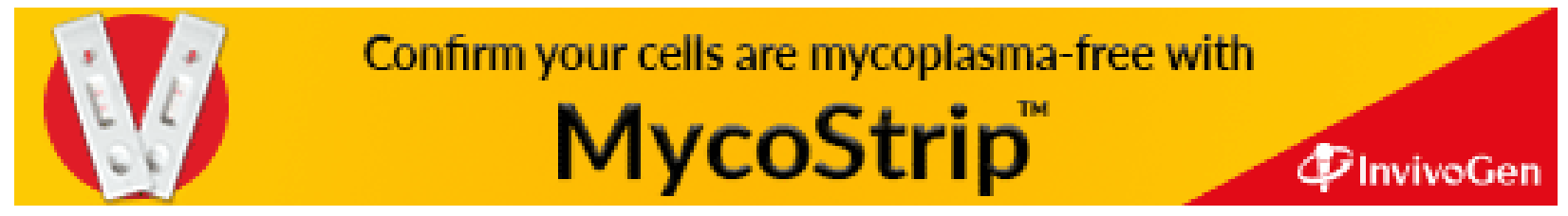

